\title{
Identifying potential restoration areas of freshwater wetlands in a river delta
}

Yanyan Hua ${ }^{\mathrm{a}}$, Baoshan Cui ${ }^{\mathrm{a},}$, Wenjie $\mathrm{He}^{\mathrm{a}}$ and Yanzi Cai ${ }^{\mathrm{a}}$

a State Key Joint Laboratory of Environmental Simulation and Pollution Control, School of Environment, Beijing Normal University, Beijing, 100875, China

Corresponding author:

Baoshan Cui ${ }^{\mathrm{a}}$

No.19 Beijing Xinjiekouwai Street, School of Environment, Beijing Normal University, Beijing, 100875,

China

Email: cuibs@bnu.edu.cn 


\begin{abstract}
Identification of potential restoration areas is significant and important for implementing a sustainable restoration project and maintaining the ecosystem integrity. We established an eco-hydrological approach to identify potential restoration areas of freshwater wetlands that should and can be restored.

Our eco-hydrological method identifies potential restoration areas from three dimensions, namely, transverse, longitudinal and vertical directions. The potential restoration areas of freshwater wetlands were determined, Based on transfer matrix analysis between freshwater wetland and other land cover types and bird habitat suitability assessment, we identified the areas that should be restored under the 1989 and 2000 goals were 36112 ha and 37230 ha, respectively. Based on hydrological connectivity and balance between ecological water supply (EWS) and ecological water requirements (EWRs), the area can be restored under the 1989 and 2000 goals were 31165 and 33963 ha, respectively. The approach and results of this study can help in future restoration efforts in the Yellow River Delta and other similar coastal wetlands.
\end{abstract}

Keywords: potential restoration areas; transfer matrix; habitat suitability; hydrological connectivity; ecological water requirements.

\title{
1. Introduction
}

The increasing value of coastal wetlands has led to a surge in interest in wetland restoration worldwide (Coats et al., 1989; Mitsch and Wang, 2000; Zhao et al., 2016). Unlike salt marshes in coastal areas, freshwater wetlands, particularly those in a river delta, are vulnerable to degradation during low inflows or periods with high sea level (Boesch et al., 1994; Stralberg et al., 2011; Wingard and Lorenz, 2014; Herbert et al., 2015; Xia et al., 2015). The success of restoration efforts depends 
largely on identifying appropriate areas for restoration. Given the increasing restoration initiatives for freshwater wetlands, the issue of identifying potential restoration areas, which involves questions on which area should be restored and which area can be restored, has become an important concern (Russefll et al., 1997; Strager et al., 2011; Sheldon et al., 2012).

With regard to the first question, freshwater wetlands are often restored for the return of land use/land cover (Stein et al., 2010) and habitat enhancement (Simaika and Samways, 2011), particularly habitats for waterbirds (Özesmi and Mitsch, 1997; Corre et al., 2012). With regard to the second question, several recent freshwater wetland restorations focused on the hydrological regime, including the timing, amplitude, frequency and duration of high water (Zedler, 2000; Hammersmark et al.,, 2005; Convertino et al., 2013). Rarely have freshwater wetland restoration projects been undertaken with the consideration of hydrological connectivity, which determines the availability of freshwater (Cabezas et al., 2008) and whether ecological water supply (EWS) can meet ecological water requirements (EWRs) (Rood et al., 2005; Erwin, 2009); hydrological connectivity and EWS are crucial in identifying areas in freshwater wetlands that can be restored..

The approaches utilized to identify potential restoration areas of freshwater wetlands have been widely investigated on the landscape scale (Simenstad et al., 2006; Maron and Cockfield, 2008; Nelson et al., 2009). From the landscape perspective, freshwater wetlands are part of the complex matrix comprising other land cover types. Measurement of the changes in land use/land cover by means of geographic information system (GIS) technology has been proved to be effective in identifying potential restoration areas (Thompson et al., 2006; Bortoleto et al., 2016). Moreover, habitat maps on the landscape scale can help identify priority areas for potential restoration (White and Fennessy, 2005; Morisette et al., 2006; Kuemmerle et al., 2011). However, the actual challenge is not only identifying 
the areas to be restored but also determining whether these areas can be restored; this restoration may be limited by hydrological connectivity and EWS. Hydrological connectivity determines the pathway of water source accessibility, and EWS determines the quality of water source accessibility. As one of the most important components of a wetland network, hydrological connectivity is usually calculated based on graph theory (Lin et al., 2009; Urban et al., 2009). EWS is a crucial component of water resources allocation and management. To calculate EWS, water balance under different scales should be considered (Xin et al., 2015).

Despite these developments, no detailed integrated approach has been presented to identify potential restoration areas, which should not only be restored, but can also be restored. Therefore, an approach for the appropriate identification of potential restoration areas for freshwater wetlands needs to be established. Such an approach should address the two aforementioned questions. We therefore present an eco-hydrological approach that is based on satellite-derived and monitoring data of the selected study area. The objective of this study is to provide a hybrid approach for the integration of ecological and hydrological indicators to identify the potential restoration areas of freshwater wetlands.

\section{Material and methods}

\subsection{Study area}

Yellow River Delta is located in the estuary of Yellow River in Dongying City of Shandong Province and at the south of Bohai Sea, China, including 3 counties (Kenli, Lijin and Hekou), which is widely recognized as having one of the highest sediment yields in the world. It has a temperate continental monsoon climate with distinct seasons and a hot rainy season. The annual mean temperature ranges from $11.5^{\circ} \mathrm{C}$ to $12.4^{\circ} \mathrm{C}$, with a frost-free period lasting 196 days. As located in a semi-arid zone, the 
delta has an average annual precipitation and average annual evaporation, with $551.6 \mathrm{~mm}$ and 1962 $\mathrm{mm}$, respectively. With the decrease of the annual runoff of the Yellow River and the diversion of freshwater to wetlands since the 1980s, large areas of freshwater wetlands (freshwater marshes in this study) have degraded, as manifested by the reverse succession of vegetation and serious destruction of waterbird habitat (Cui et al., 2009b). In 1991, the Yellow River Delta Natural Reserve (YRDNR) was established to protect original wetlands and improve habitat. Ranging from $37.5795^{\circ} \mathrm{N}$ to $38.2052^{\circ} \mathrm{N}$ and $118.5497^{\circ} \mathrm{E}$ to $119.3408^{\circ} \mathrm{E}$, the total area of the YRDNR is approximately 153000 ha, including the core, buffer and experimental area, with area of 58000 ha, 13000 ha and 82000 ha, respectively. However, freshwater wetlands in the whole river delta are still suffering from degradation. In restoration ecology theory, a desirable recovery of wetland is to restore the current state to a more "natural" state that is similar to the previous state. Therefore, two scenarios of freshwater wetland restoration were established to identify potential restoration areas based on previous state of 1989 and 2000 in this study.

\subsection{Data collection and processing}

Before processing, we prepared the following digital data: land use mapping and multi-spectral Landsat-5 TM scenes with 7 bands; historical data (i.e., bird data and annual runoff data); and field monitoring data (i.e., vegetation characteristics, water depth, and types and habitat preferences of waterbirds).

A land use mapping of China in the scale 1:50000 and vegetation mapping were supplied by the Yellow River Delta Management Bureau. Three multi-spectral Landsat-5 TM scenes with 7 bands from dates October 3, 1989, April 8, 2000 and September 11, 2010 with 30m ground resolution were available for the study area. 
Landsat TM bands 3, 4 and 5 were selected for classification due to their spectral response to chlorophyll absorption (band 3), chlorophyll reflection (band 4) and water absorption (band 5). As the TM images have already been processed by radiometric correction and geometric correction using ground control points, we processed geometric precision correction using quadratic polynomial function and resample by bilinear interpolation to control the accuracy within 0.5 pixel. The TM images were georeferenced to a UTM-WGS 84 coordinate system.

Remote sensing classification was the main process while analyzing the remote sensing data. The images in 1989, 2000, and 2010 were interpreted by using a multi-extracting method that combined supervised classification with non-supervised classification by ENVI4.3 and ArcGIS10 software. After pre-classification, artificial visual interpretation was performed to determine the wetland classification based on field observations. We developed the Yellow River Delta classification system according to the Ramsar Convention on Wetlands of International Importance, Technical Specification for Survey and Monitoring of Wetland Resources, land use mapping, and field observations. Three systems and twelve types of landscapes were distinguished: natural systems, including permanent shallow marine waters, rivers, tidal flats, freshwater marshes, and salt marshes; manmade systems, including water storage areas, aquaculture (e.g., fish/shrimp) ponds, salt ponds, and paddy fields; systems other than wetlands, including forest land, farmlands, and construction land (e.g., road/oilfield).

Bird data between 2001 and 2011 were provided by the Yellow River Delta Management Bureau. A total of 296 species were recorded in 2011, accounting for $25 \%$ of the bird resources in China. Among the bird species, we observed 10 national first-class protective species and 49 national second-class protective species. According to historical records and previous research (Duan, 2010; Xue, 2010), Charadriiformes, Anseriformes, Lariformes, Ciconiformes, and Gruiformes were selected as the 
representative and objective birds.

Annual runoff data of Lijin Hydrological Station from 1956 to 2010 were obtained from Hydrologic Annals. Data on the water into Bohai Sea, precipitation, evaporation, and out-stream water demands from 2001 to 2010 were also collected from the statistical yearbooks of Dongying and water resource bulletins of Yellow River Basin.

Field monitoring of water depth and $P$. australis, which is the dominant plant species in the freshwater wetlands of the study area, was conducted monthly from March 2009 to October 2009. Seventy-two sampling sites at intervals of $200 \mathrm{~m}$ were arranged. Three $1 \mathrm{~m} \times 1 \mathrm{~m}$ spots were set in each site. The water depth and vegetation height in each sampling spot were measured with a self-braking steel tape rule (Ref). The vegetation coverage and geographic position were also measured with a GPS (version: GARMIN eTrex Venture). The records obtained from the three sampling spots were averaged to represent the monthly characteristics of each site. Monthly data from March 2009 to May 2009, June 2009 to August 2009, and September 2009 to October 2009 were then averaged to obtain seasonal data for spring, summer, and fall, respectively. Data for winter are similar to that for fall.

\subsection{Overall Process}

A potential restoration area of a freshwater wetland should have the following properties: (1) it was a freshwater wetland in the past, (2) the habitat is not suitable in its current state, (3) the area is within the current hydrological network, and (4) EWS for the area can meet EWRs. Only by having these four characteristics can a site be identified as a potential restoration area (Fig. 1). The potential restoration areas of freshwater wetlands were determined through transfer matrix analysis of freshwater wetlands and other land cover types, habitat suitability assessment, hydrological connectivity, and balance 
between EWS and EWRs. Meanwhile, if EWS does not meet EWRs, unsuitable habitats will be prioritized for restoration over marginally suitable habitats.

Fig. 1. Illustration and example of potential restoration areas of freshwater wetlands. We define $\mathrm{P}_{i j}$ and $\mathrm{C}_{i j}$ as the grid of row $i$ column $j$ in previous state and current state, respectively. We identify the grids of freshwater wetlands converted to other land cover types from previous state to current state $\left(\mathrm{C}_{23}, \mathrm{C}_{24}\right.$, $\mathrm{C}_{38}$ and $\mathrm{C}_{78}$ ). In these grids, only $\mathrm{C}_{23}, \mathrm{C}_{38}$ and $\mathrm{C}_{78}$ are areas should be restored which with marginally suitable or unsuitable habitats. And only $\mathrm{C}_{23}$ (indirectly connected visa freshwater wetland patches to river or channels) and $\mathrm{C}_{38}$ (directly connected to river or channels) are areas can be restored and identified as potential restoration areas of freshwater wetlands. Meanwhile, if EWS does not meet EWRs, $\mathrm{C}_{38}$ (unsuitable habitat) will have priority to be restored over $\mathrm{C}_{23}$ (marginally suitable habitat).

The process for identifying potential restoration areas of freshwater wetlands was conducted through field monitoring, laboratory analysis, and remote sensing interpretation. This study is processed as follows (Fig. 2).

First, we extracted the land use/land cover maps of previous and current periods using ArcGIS and ENVI. Transfer matrix was used to analyze the dynamic changes of land use/land cover between the two periods. Areas of freshwater wetlands transferred out to other land cover types based on the previous state were identified as those should be restored, and were recorded as $L 1$.

Second, habitat suitability index model (HSI) was established in the form of linear function to assess habitat suitability for waterbirds. Unsuitable and marginally suitable habitats were also identified as those should be restored. Overlapped with areas identified by transfer matrix of freshwater wetlands, we were able to identify integrated areas should be restored which were recorded as $L 2$. 
Next, hydrological networks in previous and current period were designed based on graph theory with linear wetlands (e.g., natural river channels, artificial river channels, and ditches) as edges and patch wetlands (e.g., reservoirs and manmade wetlands) and confluences as nodes. The designed hydrological networks were undirected and no-weight networks that did not consider the amount and direction of flow of this study. To reduce redundant loops, links, and nodes within complex networks, we optimized the hydrological networks by applying the shortest path algorithm of graph theory (Cui et al., 2009a). Considering hydrological connectivity, freshwater wetland patches within the hydrological networks were identified as areas can be restored and were recorded as $L 3$.

Meanwhile, EWRs and EWS that could be diverted to freshwater wetlands were calculated. In high flow and normal years, EWS are sufficient to meet the EWRs. Therefore, we mainly calculated EWS of the study area in the dry year (75\% runoff guaranteed frequency) and very dry year (95\% runoff guaranteed frequency). If EWS meet EWRs, all the patches within $L 3$ were identified as potential restoration areas; otherwise, the patches with lower habitat suitability were prioritized.

Fig. 2. Flowchart of the proposed methodology

\subsection{Detailed methods}

\subsubsection{Analysis of land use/land cover}

The area of landscape (TA), percentage of landscape (PLAND), and change in the intensity of the wetland area $(W C I)$ were analyzed to demonstrate the changing process of the landscape from 1989 to 2010. The spatial pattern analysis software FRAGSTATS 4.0 was applied to calculate TA and PLAND. WCI was calculated as follows:

$$
\begin{aligned}
& W C I_{i, t \rightarrow t+n}=W C S_{i, t \rightarrow t+n} / W A_{i, t+n} \\
& W C S_{i, t \rightarrow t+n}=\left(W A_{i, t+n}-W A_{i, t}\right) / n
\end{aligned}
$$


where $t$ is the variable of time; $n$ is the length of a period; $W C S_{i, t \rightarrow t+n}$ and $W C I_{i, t \rightarrow t+n}$ are $W C S$ and $W C I$ between the time $t$ and $t+n$, respectively; WCS is the change in the speed of the wetland area; and $W A_{i, t}$ and $W A_{i, t+n}$ are the areas at time $t$ and $t+n$, respectively.

To illustrate the dynamic changes in wetlands, further analysis of the transfer matrix of land use was conducted with ArcGIS 10.

Spatial pattern analysis was developed using Fragstats4.0 and Origin 8. Six landscape indicators were selected to present the changes of landscape pattern, including Number of Patches $(N P)$, Patch Density $(P D)$, Largest Patch Index (LPI), Landscape Shape Index (LSI), Patch Cohesion Index (COHESION) and Simpson's Diversity Index (SHDI).

\subsubsection{Assessment of habitat suitability}

Multicriteria spatial decision support systems (MC-SDSS) have been widely used to solve spatial problems and have been proven effective (Ferretti and Pomarico, 2013; Ferretti and Montibeller, 2016).

With the framework of MC-SDSS, appropriate indicators and a weight calculation method were selected to establish $H S I$, which represent the overall habitat suitability of the study area.

HSI is expressed as follows:

$$
H S I=\sum_{j=1}^{n} w_{j} \sum_{i=1}^{m} p_{i} v_{i j}
$$

where $w_{j}$ is the contribution (or weight) of factor $j$ to habitat suitability; $p_{i}$ is the relative importance of bird order $i$ in the study area; $v_{i j}$ is the value of the habitat suitability for bird order $i$ under the influence of factor $j ; i=1,2, \ldots, m ; m$ is the total number of bird orders analyzed; $j=1,2, \ldots, n$; and $n$ is the total number of factors that influence habitat suitability.

The effects of different factors on the habitat suitability of birds differed. We mainly considered four factors that influence habitat suitability, namely, distance to waters from each square grid cell to the nearest river or channel, preference for different landscape types, normalized difference vegetation 
index (NDVI), and distance to construction land. Rank correlation analysis (G1 method) (Guo, 2002) was introduced to calculate $w_{i}$ in HSI. $p_{i}$ was determined according to bird protection class of national key protected species of China, the number of each bird order, and expertise. In this study, $v_{i j}$ was divided into three levels, namely, unsuitable, marginally suitable, and suitable habitats with values of 1 , 5, and 9, respectively. In determining $v_{i j}$, we consulted experts, examined literature, and analyzed the habits of each bird order through long-term field observations.

\subsubsection{Analysis of hydrological connectivity}

Hydrological networks of 1989, 2000, and 2010 were designed according to graph theory, with linear wetlands (e.g., natural river channels, artificial river channels, ditches) as edges and patch wetlands (e.g., reservoirs and man-made wetlands) and confluences as nodes. The functional effectiveness of the hydrological networks was considered to guarantee the accessibility of freshwater to the potential restoration areas and was assessed with the Gamma index of connectivity $(\gamma) \cdot \gamma$ can be calculated as follows:

$$
\gamma=L / L_{\max }, \quad L_{\max }=3(V-2) \quad(V \geq 3, V \in N)
$$

where $\gamma$ is the gamma index of connectivity, $L$ is the number of linkages, and $V$ is the number of nodes. The value of $\gamma$ ranges from 0 to 1 . The higher the index is, the better the connectivity of hydrological network is.

\subsubsection{Calculation of EWRs and EWS}

The calculation of EWRs was performed as follows:

$$
\begin{gathered}
E W R s=W_{p}+E-P \\
W_{p}=\sum_{i=1}^{i=n} A h_{i}
\end{gathered}
$$

where $W_{p}$ is ecological water requirements for $P$. australis; $E$ is evaporation; $P$ is precipitation; $A$ 
is the total area of potential restored patches; $h_{\mathrm{i}}$ is the lower limit of the optimum threshold of water depth in time period $i ; i=1,2,3, \ldots, n$; and $n$ is the total number of time periods. In this study, $n$ equals 4, which represents the four seasons in a year. The optimum threshold of water depth was determined through regression analysis of water depth and the normalization value of the ecological characteristics (height and coverage in this study) of $P$. australis. We normalized height and coverage by means of maximum values in the corresponding time period.

The EWS of the study area mainly came from Yellow River. A certain amount of water provided to Bohai Sea should also be guaranteed. The water balance in the study area can be expressed as follows:

$$
E W S=F-W_{s}-W_{o u t}
$$

where $E W S$ is freshwater supplied to the study area; $F$ is the runoff of Yellow River recorded in Lijin Hydrographic Station, which is the nearest hydrographic station to the study area and the estuary of Yellow River; $W_{s}$ is freshwater provided to Bohai Sea; and $W_{\text {out }}$ is the out-stream water demands, including ecological, domestic, and production water demands. In this study, $F$ is the runoff in $75 \%$ percentile and $95 \%$ percentile of the long-term hydrological series from 1956 to 2010 . $W_{s}$, and $W_{\text {out }}$ were calculated by averaging the observed record of water to Bohai Sea and the out-stream water demands from 2001 to 2010, respectively.

\section{Results}

\subsection{Which area should be restored?}

Dramatic decreases in natural wetlands and increases in man-made lands dominated the land use/land cover changes detected from 1989 (Fig. 3A) to 2000 (Fig. 3B) and 2010 (Fig. 3C). The change in the intensity (WCI) of natural wetlands was obvious during this period. Between 1989 and 2000, 
natural wetlands increased by $14.9 \%$. The severe decrease in natural wetlands accelerated by nearly $30 \%$ between 2000 and 2010. From 1989 to 2010, the extent of natural wetlands decreased by 18.2\%. Most of the man-made land expansions came at the expense of natural wetlands, with a total increase of $15.7 \%$ over a period of 21 years.

Fig. 3. Land use/land cover of the study area in 1989 (a), 2000 (b), and 2010 (c). Three classes and twelve types of landscapes were distinguished.

Freshwater marshes demonstrated a trend similar to that demonstrated by total natural wetlands. The transformations in 1989, 2000, and 2010 were frequent (Fig. 4). During the periods of 2000 to 2010 and 1989 to 2010,26919 ha $(33.7 \%$ of the total area in 2000$)$ and 29809 ha $(39.8 \%$ of the total area in 1989) of freshwater marshes were converted to farmlands, respectively, and nearly 12808 ha (16\%) and 8391 ha $(11.2 \%)$ were converted to water storage areas, salt marshes, and aquaculture ponds, respectively. The main category shifted to freshwater marshes consisting of tidal flats, with 18620 and 14514 ha between 2000 and 2010 and between 1989 and 2010, respectively.

Fig. 4. Transformation of freshwater marshes in 1989, 2000, and 2010. The bold line with an arrow indicates the transferred percentage of freshwater marshes. The thicker the line is, the higher the transferred percentage is.

The landscape pattern changed over time (Fig. 5). The NP and $P D$ of freshwater marshes and other landscape patterns showed minimal change, except for permanent shallow marine water, whereas the LPI of freshwater marshes remained stable. The degree of landscape fragmentation in freshwater marshes decreased as LSI declined from 1989 to 2010. Most of the natural wetlands presented high degree of cohesion with a high value of COHESION. SHDI presented a decreasing tendency during the two-decade period. 
Fig. 5. Changes in the landscape pattern index: $(\mathrm{A})$ number of patches $(N P),(\mathrm{B})$ patch density $(P D),(\mathrm{C})$ largest patch index $(L P I),(\mathrm{D})$ landscape shape index $(L S I),(\mathrm{E})$ patch cohesion index (COHESION), and (F) Simpson's diversity index (SHDI) in 1989, 2000, and 2010.

Considering that the areas of freshwater wetlands were converted to other land cover types according to the previous state, the potential restoration area $L 1$ under the 1989 and 2000 goals was 50356 ha (the distribution is shown in Fig. 6A) and 54766 ha (the distribution is shown in Fig.6B), respectively.

Fig. 6. Potential restoration areas $L 1$ according to the 1989 (A) and 2000 (B) goals.

With the space analysis function of ArcGIS10, we established the HSI model according to the index system of HSI (Table 1). By using the HSI established in this study, the calculation results were divided into three levels, namely, unsuitable, marginally suitable, and suitable with $H S I$ values of $<8$, from 8 to 12 and $>12$, respectively. The results showed that more than $70 \%$ of the study areas were marginally suitable habitats, whereas only a small number of areas consisting of high urban density and forest land with high canopy density were unsuitable habitats (Fig. 7A). Marginally suitable habitats were mainly distributed in YRDNR (Fig. 7A). Suitable habitats were concentrated on both sides of the Yellow River; its outlet to the sea and its old drainage area, which had minimal human influence, comprise the intersection area of freshwater wetlands (where birds bred) and beach wetlands (where birds foraged for food and rested). The intensity of towns around YRDNR was low; therefore, the influence on habitats was not destructive, although Shengli Oilfield is located in this area. We obtained $L 2$ by overlapping the distribution of the three-level habitat with $L 1$ and excluding areas with a suitable habitat from L1. Correspondingly, the areas that should be restored under the 1989 and 2000 goals were 36112 ha (Fig. 7B) and 37230 ha (Fig. 7C), respectively. In considering the order to be restored, the patches in unsuitable habitats of the freshwater wetland patches should be given priority. 
Fig. 7. Distribution of the three-level habitat (A) and potential restoration areas $L 2$ based on the 1989 (B) and 2000 (C) goals. 
Table 1 Index system of HSI.

\begin{tabular}{|c|c|c|c|c|c|c|c|c|}
\hline \multirow[t]{2}{*}{ Factors } & \multirow{2}{*}{$\begin{array}{l}\text { Weights } \\
w\end{array}$} & \multirow[t]{2}{*}{ Items } & & \multicolumn{5}{|c|}{ Assigned value $v$} \\
\hline & & & & $C h$ & $A n$ & $L a$ & $C i$ & $G r$ \\
\hline \multirow[t]{6}{*}{ Distance to waters (m) } & 0.31 & $<500$ & & 9 & 9 & 9 & & \\
\hline & & $500-1000$ & & 5 & 5 & 5 & & \\
\hline & & $>1000$ & & 1 & 1 & 1 & & \\
\hline & & $<800$ & & & & & 9 & 9 \\
\hline & & $800-1200$ & & & & & 5 & 5 \\
\hline & & $>1200$ & & & & & 1 & 1 \\
\hline \multirow[t]{8}{*}{ Landscape types } & 0.22 & Freshwater marsh & & 5 & 5 & 1 & 5 & 5 \\
\hline & & Tidal flat & & 9 & 9 & 9 & 9 & 9 \\
\hline & & Salt pond & & 1 & 1 & 1 & 1 & 1 \\
\hline & & Aquaculture pond & & 9 & 9 & 9 & 5 & 5 \\
\hline & & Paddy field & & 1 & 5 & 5 & 5 & 9 \\
\hline & & Forest land & & 1 & 1 & 1 & 1 & 5 \\
\hline & & Farmland & & 1 & 1 & 1 & 1 & 1 \\
\hline & & Salt marsh & & 1 & 1 & 1 & 1 & 1 \\
\hline \multirow[t]{3}{*}{ NDVI } & 0.04 & $>0.2$ & & 9 & 9 & 9 & 9 & 9 \\
\hline & & $0-0.2$ & & 5 & 5 & 5 & 5 & 5 \\
\hline & & $<0$ & & 1 & 1 & 1 & 1 & 1 \\
\hline \multirow{9}{*}{$\begin{array}{l}\text { Distance to construction } \\
\text { land }(\mathrm{m})\end{array}$} & 0.43 & to oil field & $<30$ & 1 & 1 & 1 & 1 & 1 \\
\hline & & & $<300$ & 5 & 5 & 5 & 5 & 5 \\
\hline & & & $>300$ & 9 & 9 & 9 & 9 & 9 \\
\hline & & to rural settlements & $<270$ & 1 & 1 & 1 & 1 & 1 \\
\hline & & & $<2730$ & 5 & 5 & 5 & 5 & 5 \\
\hline & & & $>2730$ & 9 & 9 & 9 & 9 & 9 \\
\hline & & to urban settlements & $<810$ & 1 & 1 & 1 & 1 & 1 \\
\hline & & & $<7200$ & 5 & 5 & 5 & 5 & 5 \\
\hline & & & $>7200$ & 9 & 9 & 9 & 9 & 9 \\
\hline \multicolumn{4}{|c|}{ Relative importance of bird order $p$} & 0.1 & 0.2 & 0.1 & 0.2 & 0.4 \\
\hline
\end{tabular}

Notes: $p$ is the relative importance of bird order in the study area.

$w$ is the weight (or contribution) of influence factor to habitat suitability of bird order.

$v$ is the value of habitat suitability for bird order under the influence of certain factor: suitable $(v=9)$, marginally suitable $(v=5)$, unsuitable $(v=1)$.

Bird order: Charadriiformes (Ch), Anseriformes (An), Lariformes (La), Ciconiformes (Ci), Gruiformes (Gr). 


\subsection{Which area can be restored?}

Hydrological networks of 1989 (Fig. 8A), 2000 (Fig. 8B), and 2010 (Fig. 8C) were designed and optimized by applying the shortest path algorithm of graph theory. $\gamma$ in 1989, 2000, and 2010 was $0.76,0.50$ and 0.31 , respectively. Restoring degraded or occupied freshwater marshes under the current hydrological networks is feasible, except for 1989-1 (No. 1 patch in 1989, similar hereinafter) and 2000-1, which are beyond the hydrological networks with an area of 4947 and 3267 ha, respectively. By overlapping the hydrological networks with potential restoration area $L 2$ and deleting 1989-1 and 2000-1, we obtained the potential restoration area $L 3$ under the 1989 and 2000 goals, with 31165 and 33963 ha, respectively (Fig. 9).

Fig. 8. Hydrological networks of 1989 (A), 2000 (B) and 2010 (C)

Fig. 9. Potential restoration areas $L 3$ based on the 1989 (A) and 2000 (B) goals.

The coverage and height of $P$. australis versus water depth showed single-peak curves in spring, summer, and fall (Fig. 10). We assumed that $P$. australis would have a good performance when the normalized values of both coverage and height are higher than 0.6. Correspondingly, the optimum thresholds of water depth in spring, summer and fall-winter were $4.1 \mathrm{~cm}$ to $8.9 \mathrm{~cm}, 6 \mathrm{~cm}$ to $16.3 \mathrm{~cm}$ and $1.6 \mathrm{~cm}$ to $22.5 \mathrm{~cm}$, respectively. With Eq. (5), we calculated the minimum annual EWRs for patches within potential restoration area $L 3$ (Fig. 9),. The calculated values are $4.33 \times 10^{8} \mathrm{~m}^{3}$ and $4.72 \times 10^{8} \mathrm{~m}^{3}$ under the 1989 and 2000 goals, respectively.

Fig. 10 Relationship between water depth and normalized coverage and height of $P$. australis in sping ((a) and (b)), summer ((c) and (d)), and fall ((d) and (e)). The dashed curves indicate $\pm 95 \%$ confidence interval, which correspond to the fitted model.

The annual runoff values of the Lijin Hydrological Station in dry years (75\% guaranteed runoff frequency) and very dry years (95\% guaranteed runoff frequency) were $156.31 \times 10^{8} \mathrm{~m}^{3}$ and $47.75 \times 10^{8} \mathrm{~m}^{3}$, respectively. The sea-going water of the Yellow River has been gradually decreasing since the 1950s; critical levels were 
reached in the late 1980 s to the early 2000 s. Therefore, the situation of the estuary in the late 1980 s to the early 2000s was set as the minimum ecological protection target. Accordingly, the average sea-going water during this period $\left(141.91 \times 10^{8} \mathrm{~m}^{3}\right)$ was set as the minimum demand, and that with $95 \%$ guaranteed inflow frequency $\left(42.94 \times 10^{8} \mathrm{~m}^{3}\right)$ was set as the lower limit. The water diverted to Hekou, Lijin, and Kenli as domestic, production, and off-stream ecological waters under $75 \%$ guaranteed inflow frequency reached $5.55 \times 10^{8} \mathrm{~m}^{3}$. In very dry years, such an amount was not allowed to be diverted from the Yellow River.

Consequently, the EWS to the study areas under $75 \%$ and $95 \%$ guaranteed inflow frequency was $8.85 \times 10^{8} \mathrm{~m}^{3}$ and $4.81 \times 10^{8} \mathrm{~m}^{3}$, respectively. With regard to the corresponding EWRs, the freshwater inflows met the goals under 1989 and 2000. Therefore, all the freshwater marsh patches within the hydrological networks in L3 (Fig. 10) were identified as potential restoration areas, with an area of 31165 and 33963 ha under the 1989 and 2000 goals, respectively.

\section{Discussion}

Ecologists are exploring models, frameworks, tools and principles that provide a link between the theory and practice of identification of potential restoration areas (White and Fennessy, 2005; Morisette et al., 2006; Sheley, Mangold and Anderson, 2006; Budy and Schaller, 2007; Nicol and Possingham, 2010; Orsi et al., 2011). By applying an eco-hydrological approach that is based on the transformation of land use/land cover, bird habitat suitability assessment, hydrological connectivity, and balance between EWS and EWRs, we were able to identify spatially-explicit potential restoration areas of freshwater marshes under long-term goals.

The approach provides a quantitative and spatial framework to help understand the performance of freshwater wetland restoration that has been lacking in previous discussions (Bedford, 1996; Russefll et al., 1997; Newbold 2005) and in implementation of restoration strategies. The goal of the approach is to optimize the location of freshwater wetland restoration projects to facilitate the efficient future use of water resources and 
reduce the likelihood of associated ecological loss. Previous work on spatial planning and optimization for freshwater wetland management has not addressed the availability of water resources and dynamic change issues (Heiner et al., 2011). Our eco-hydrological method identifies potential restoration areas from three dimensions, namely, transverse, longitudinal and vertical directions. Transverse direction refers to freshwater wetland patches. Longitudinal direction refers to the hydrological network, and vertical direction refers to temporal variation. The dynamic changes in the types and structures of land use/land cover and the habitat suitability of each patch determine the spatial distribution of a potential restoration area from the horizontal and vertical dimensions; hydrological connectivity guarantees water source accessibility from the longitudinal dimension. Multi-element and multi-dimension make the identification process more highly practical.

The results indicate that the eco-hydrological approach is effective in delineating the potential restoration scale, including area and distribution. Results showed that not all of the freshwater marshes converted to other landscape patterns can be restored to their previous or original state because of the restrictions imposed by habitat suitability, hydrology accessibility, or source of freshwater.

Most wetland restoration plans are implemented through "engineered" actions that improve or recreate wetland structures and processes (Simenstad et al., 2006). In most cases, potential restoration areas are determined according to specific goals without consideration of the modification of the integrate function.Such engineered projects may cause different degrees of negative effects on the wetland ecosystem in the long term (Jackson and Pringle 2010; Moreno-Mateos et al., 2012). Hydrological networks provide an effective and ecological means to reduce or avoid such negative effects as much as possible (Jansson, Nilsson and Malmqvist, 2007; Paillex et al., 2009). As shown in Fig. 5, the slight fragmentation and strong tightness of patches provide a possibility to restore by patches through related hydrological networks. Hydrological networks showed weak connectivity in 2010; the $\gamma$ of hydrological networks declined from 0.76 to 0.31 during a two-decade period. 
This finding demonstrates the necessity and urgency of restoring freshwater marshes. Meanwhile, the hydrological networks provided access to freshwater from the Yellow River to the restored patches. The hydrological networks also help modify the potential restoration area identified through landscape transformations and habitat suitability assessments by excluding patches numbered 1989-1 and 2000-1 (Fig. 9).

Given that hydrology is one of the three components of wetlands (the other two are soil and biont, water control is the key to wetland restoration (Zedler and Kercher, 2005; Acreman et al., 2007). In this study, the restoration schemes had undertaken eco-hydrological research to ensure that the correct amount of water is available at the right time of year. The focus of the eco-hydrological work was to compare the requirements of the target habitats with practicality and likelihood that these conditions could be provided in the potential restoration area. The relationship between EWRs and the area of freshwater marshes potentially restored was made under regression analysis approach. Our results indicated EWS can meet the EWRs of potential restoration area determined by landscape transformation, assessment of $H S I$ and hydrological connectivity, thus all the patches were identified as the potential restoration scale. If not, potential restoration scale should be identified according to both relationship between the EWRs and the area and priority of patches.

Present restoration project implemented since 2002 is not inconsistent with the potential restoration scale in our study. Part of the areas of 2000-7 (Fig. 8B) and 2010-11 (Fig. 8C) patches located to the south of Yellow River were out of the potential restoration areas, yet in the present restoration project. As described in Fig. 8A, these parts are suitable habitats which are unnecessary to restore. If continue to "restore" by supplying freshwater to these areas, these parts may change to lower level habitats. Since 1989, SHDI has already showed a trend of gradually reduce (Fig. 5F). This may be attributed to the following two reasons: 1) a large number of cultivated lands were occupied by farmland; and 2) implementation of freshwater wetland restoration project made the original wetland landscape gradually single. In the long run, decrease of SHDI 
may have a negative impact on habitat suitability of birds prefer to other landscape, such as Anseriformes and Charadiiformes with preference of open water area and tidal flat, respectively (Summers, Underhill LG and Simpson, 2002). Hua et al (2012) have demonstrated that the habitat suitability index increased in the first 6 years yet declined after that in the YRDNR. Consequently, potential restoration area of freshwater marshes should be identified by an eco-hydrological approach proposed in this study, which integrated landscape, biological suitability and hydrology condition (including hydrology quantity and availability). Unreasonable restoration would break the ecosystem integrity both structural and functional. It is likely that our research will offer scientific basis in such freshwater marsh restoration process.

\section{Conclusion}

The proposed eco-hydrological approach, described in this paper for identifying potential restoration area of freshwater wetlands, represents an explicit and practicable solution for questions "which area should be restored?" and "which area can be restored?". Establishment of multi-objective HSI modified areas to be restored, while hydrological networks and balance between EWRs and EWS modified areas can be restored. Our work identified scale and distribution of potential restoration areas based on different goals, and suggests not all the converted or disturbed freshwater wetland patches are suitable for restoration. The areas identified in our study offered an important guidance for wetland managers to select freshwater wetland restoration areas.

In the case study of the Yellow River Delta, we considered four factors that affect wetlands function: position in the landscape (geomorphic setting), habitat suitability, water source accessibility (hydrological connectivity), and EWRs availability for the freshwater wetlands to restore; while we did not take into account some other factors may influence ecosystem health (e.g., water quality of adjacent waters) (Tan et al., 2015). A possible extension for this approach would be to integrate them into a multi-objective framework. 
Moreover, even the potential restoration area identified by integrated approach can be modified by policy interventions. What is yet lacking is the systematic adoption of a framework for the spatial targeting of policy interventions which can be used for wetlands managers to improve decision making in terms of effectiveness, efficiency, equity or public acceptability. Another caveat to our approach is that we did not include changes in climate and natural succession of vegetation in the integrated approach to date. And all of which above are likely to influence identification of potential restoration areas of freshwater wetlands and also are crucial next steps in the application of the integrated approach.

\section{Acknowledgements}

This research was funded by National Key Basic Research Program of China (2013CB430406), China National Funds for Distinguished Young Scientists (51125035), and National Science Foundation for Innovative Research Group (51121003). We would like to acknowledge staffs in scientific research station from the Yellow River Delta Management Bureau for their help in historical data compilation and fieldwork.

\section{References}

Acreman, M.C., Fisher, J., Stratford, C.J., Mould, D.J., Mountford, J.O., 2007. Hydrological science and wetland restoration: some case studies from Europe. Hydrol. Earth Syst. Sci. 11, 158-169.

Bedford, B.A., 1996. The need to define hydrologic equivalence at the landscape scale for freshwater wetland mitigation. Ecol. Appl. 6, 57-68. DOI: 10.2307/2269552.

Boesch D.F., Josselyn M.N., Mehta A.J., Morris J.T., Nuttle W.K., Simenstad C.A., Swift D.J.P., 1994. Scientific assessment of coastal wetland loss, restoration and management in Louisiana. J. Coastal Res. $20,1-36$.

Bortoleto, L.A., Figueira, C.J.M., Dunning, J.B., Rodgers, J., da Silva, A.M. 2016. Suitability index for 
restoration in landscapes: An alternative proposal for restoration projects. Ecol. Indic. 60, 724-735. DOI: 10.1016/j.ecolind.2015.08.002.

Budy, P., Schaller, H., 2007. Evaluating tributary restoration potential for pacific salmon recovery. Ecol. Appl. 17, 1068-1086. DOI: 10.1890/06-0022.

Cabezas, A., González, E., Gallardo, B., Garcia, M., González, M., Comín, F.A., 2008. Effects of hydrological connectivity on the substrate and understory structure of riparian wetlands in the Middle Ebro River (NE Spain): implications for restoration and management. Aquat. Sci. 70, 361-376. DOI: $10.1007 / \mathrm{s} 00027-008-8059-4$.

Coats, R., Swanson, M., Williams, P., 1989. Hydrologic analysis for coastal wetland restoration. Environ. Manage. 13, 715-727. DOI: 10.1007/BF01868311.

Convertino, M., Baker, K.M., Vogel, J.T., Lu, C., Suedel, B., Linkov, I. 2013. Multi-criteria decision analysis to select metrics for design and monitoring of sustainable ecosystem restorations. Ecol. Indic. 26, 76-86. DOI: 10.1016/j.ecolind.2012.10.005.

Corre, M.L., Jaeger, A., Pinet, P., Kappes, M.A., Weimerskirch, H., Catry, T., Ramos, J.A., Russel, J.C., Shah, N., Jaquemet, S., 2012. Tracking seabirds to identify potential Marine Protected Area in the tropical western India Ocean. Biol. Conserv. 156, 83-93. DOI: 10.1016/j.biocon.2011.11.015.

Cui, B.S., Wang, C.F., Tao, W.D., You, Z.Y., 2009a. River channel network design for drought and flood control: A case study of Xiaoqinghe River basin, Jinan City, China. J. Environ. Manage. 90, 3675-3686. DOI: 10.1016/j.jenvman.2009.07.010.

Cui, B.S., Yang, Q.C., Yang, Z.F., Zhang, K.J., 2009b. Evaluating the ecological performance of wetland restoration in the Yellow River Delta, China. Ecol. Eng. 35, 1090-1103. DOI: 10.1016/j.ecoleng.2009.03.022. 
Duan, Y.B., 2010. Behavior and habitat selection of oriental white stork in breeding season in the Yellow River estuary nature. Heilongjiagn: Northeast Forestry Unversity. (in Chinese)

Erwin, K.L., 2009. Wetlands and global climate change: the role of wetland restoration in a changing world.

Wetl. Ecol. Manag. 17, 71-84. DOI: 10.1007/s11273-008-9119-1.

Ferretti, V., Montibeller, G., 2016. Key challenges and meta-choices in designing and applying multi-criteria spatial decision support systems. Decis. Support Syst. 84, 41-52. DOI: 10.1016/j.dss.2016.01.005.

Ferretti, V., Pomarico, S., 2013. Ecological land suitability analysis through spatial indicators: an application of the Analytic Network Process technique and Ordered Weighted Average approach, Ecol. Indic. 34, 507-519. DOI: 10.1016/j.ecolind.2013.06.005.

Guo, Y.J., 2002. Comprehensive evaluation theory and methods. Beijing: Science Press. (in Chinese)

Hammersmark, C.T., Fleenor, W.E., Schladow, S.G., 2005. Simulation of flood impact and habitat extent for a tidal freshwater marsh restoration. Ecol. Eng. 25, 137-152. DOI: 10.1016/j.ecoleng.2005.02.008.

Heiner, M., Higgins, J., Li, X., Baker, B., 2011. Identifying freshwater conservation priorities in the Upper Yangtze River Basin. Freshwater Biol. 56, 89-105. DOI: 10.1111/j.1365-2427.2010.02466.x.

Herbert, E.R., Boon, P., Burgin, A. J., Neubauer, S. C., Franklin, R. B., Ardón, M., Hopfensperger, K. N., Lamers, L. P. M., Gell. P., 2015. A global perspective on wetland salinization: ecological consequences of a growing threat to freshwater wetlands. Ecosphere 6, 206. DOI: 10.1890/ES14-00534.1.

Hua, Y.Y., Cui, B.S., He, W.J., 2012. Changes in waterbirds habitat suitability following wetland restoration in the Yellow River Delta, China. Clean-Soil, Air, Water 40, 1076-1084. DOI: 10.1002/clen.201200064.

Jackson, C.R., Pringle, C.M., 2010. Ecological benefits of reduced hydrologic connectivity in intensively developed landscapes. BioScience 60, 37-46. DOI: 10.1525/bio.2010.60.1.8.

Jansson, R., Nilsson, C., Malmqvist, B., 2007. Restoring freshwater ecosystems in riverine landscapes: the 
roles of connectivity and recovery processes. Freshwater Biol. 52, 589-596. DOI: 10.1111/j.1365-2427.2007.01737.x.

Kuemmerle, T., Radeloff, V.C., Perzanowski, K., Kozlo, P., Sipko, T., Khoyetskyy, P., Bashta, A.T., Chikurova, E., Parnikoza, I., Baskin, L., Angelstam, P., Waller, D.M., 2011. Predicting potential European bison habitat across its former range. Ecol. Appl. 21, 830-843. DOI: 10.1890/10-0073.1.

Lin, T., Lin, J., Cui, S., Cameron, S., 2009. Using a network framework to quantitatively select ecological indicators. Ecol. Indic. 9, 1114-1120. DOI: 10.1016/j.ecolind.2008.12.009.

Maron, M., Cockfield, G., 2008. Managing trade-offs in landscape restoration and revegetation projects. Ecol. Appl. 18, 2041-2049. DOI: 10.1890/07-1328.1.

Mitsch, W.J., Wang, N.M., 2000. Large-scale coastal wetland restoration on the Laurentian Great Lakes: determining the potential for water quality improvement. Ecol. Eng. 15, 267-282. DOI: 10.1016/S0925-8574(00)00081-1.

Moreno-Mateos, D., Power, M.E., Comı'n, F.A., Yockteng, R., 2012. Structural and Functional Loss in Restored Wetland Ecosystems. PLoS Biol. 10, e1001247. DOI: 10.1371/journal.pbio.1001247.

Morisette, J.T., Jarnevich, C.S., Ullah, A., Cai, W.J., Pedelty, J.A., Gentle, J.E., Stohlgren, T.J., Schnase, J.L., 2006. A tamarisk habitat suitability map for the continental United States. Front Ecol. Environ. 4, 11-17. DOI: 10.1890/1540-9295(2006)004[0012:ATHSMF]2.0.CO;2.

Nelson, E., Mendoza, G., Regetz, J., Polasky, S., Tallis, H., Cameron, D.R., Chan, K.M.A., Daily, G.C., Goldstein, J., Kareiva, P.M., Lonsdorf, E., Naidoo, R., Ricketts, T.H., Shaw, M.R., 2009. Modeling multiple ecosystem services, biodiversity conservation, commodity production, and tradeoffs at landscape scales. Front. Ecol. Environ. 7, 4-11. DOI: 10.1890/080023.

Newbold, S.C., 2005. A combined hydrologic simulation and landscape design model to prioritize sites for 
wetlands restoration. Environ. Model. Assess. 10, 251-263. DOI: 10.1007/s10666-005-9002-x.

Nicol, S.C., Possingham, H.P., 2010. Should metapopulation restoration strategies increase patch area or number of patches? Ecol. Appl. 20, 566-581. DOI: 10.1890/08-2216.1.

Özesmi, U., Mitsch, W.J., 1997. A spatial model for the marsh-breeding red-winged blackbird (Agelaius phoeniceus L.) in coastal Lake Erie wetlands. Ecol. Model. 101, 139-152. DOI: 10.1016/S0304-3800(97)01983-2.

Orsi, F., Geneletti, D., Newton, A.C. 2011. Towards a common set of criteria and indicators to identify forest restoration priorities: An expert panel-based approach. Ecol. Indic. 11, 337-347. DOI: 10.1016/j.ecolind.2010.06.001.

Paillex, A., Dolédec, S., Castella, E., Mérigoux, S., 2009. Large river floodplain restoration: predicting species richness and trait responses to the restoration of hydrological connectivity. J. Appl. Ecol. 46, 250-258. DOI: 10.1111/j.1365-2664.2008.01593.x.

Rood, S.B., Samuelson, G.M., Braatne, J.H., Gourley, C.R., Hughes, F.M.R., Mahoney, J.M., 2005. Managing river flows to restore floodplain forests. Front. Ecol. Environ. 3: 193-201. DOI: 10.1890/1540-9295(2005)003[0193:MRFTRF]2.0.CO;2.

Russefll, G.D., Hawkins, C.P., O’Neill, M.P., 1997. The role of GIS in selecting sites for riparian restoration based on hydrology and land use. Restor. Ecol. 5, 56-68. DOI: 10.1111/j.1526-100X.1997.00056.x.

Sheldon, F., Peterson, E.E., Boone, E.L., Sippel, S., Bunn, S.E., Harch, B.D., 2012. Identifying the spatial scale of land use that most strongly influences overall river ecosystem health score. Ecol. Appl. 22, 2188-2203. DOI: $10.1890 / 11-1792.1$.

Sheley, R.L., Mangold, J.M., Anderson, J.L., 2006. Potential for successional theory to guide restoration of invasive-plant-dominated rangeland. Ecol. Monogr. 76, 365-379. DOI: 
10.1890/0012-9615(2006)076[0365:PFSTTG]2.0.CO;2.

Simaika, J.P., Samways, M.J. 2011. Comparative assessment of indices of freshwater habitat conditions using different invertebrate taxon sets. Ecol. Indic. 11, 370-378. DOI: 10.1016/j.ecolind.2010.06.005.

Simenstad, C., Reed, D., Ford, M., 2006. When is restoration not? Incorporating landscape-scale processes to restore self-sustaining ecosystems in coastal wetland restoration. Ecol. Eng. 26, 27-39. DOI: 10.1016/j.ecoleng.2005.09.007.

Stein, E.D., Dark, S., Longcore, T., Grossinger, R., Hall, N., Beland, M., 2010. Historical ecology as a tool for assessing landscape change and informing wetland restoration priorities. Wetlands 30, 589-601. DOI: 10.1007/s13157-010-0050-x.

Strager, M.P., Anderson, J.T., Osbourne, J.D., Fortney, R., 2011. A three- tiered framework to select, prioritize, and evaluate potential wetland and stream mitigation banking sites. Wetl. Ecol. Manag. 19, 1-18. DOI: 10.1007/s11273-010-9194-y.

Stralberg, D., Brennan, M., Callaway, J.C., Wood, J.K., Schile, L.M., Jongsomjit, D., Kelly, M., Parker, V.T., Crooks, S., 2011. Evaluating tidal marsh sustainability in the face of sea-level rise: a hybrid modeling approach applied to San Francisco Bay. PLoS ONE 6, e27388. DOI: 10.1371/journal.pone.0027388.

Summers, R.W., Underhill, L.G., Simpson, A., 2002. Habitat preferences of waders (Charadrii) on the Coast of the Orkney Islands: twelve species of wader were surveyed on 494 coastal sections, revealing features in addition to substratum type that are important in habitat selection. Bird Study 49,60-66. DOI: $10.1080 / 00063650209461245$.

Tan, X., Xia, X.L., Li, S.Y., Zhang, Q.F., 2015. Water quality characteristics and integrated assessment based on multistep correlation analysis in the Danjiangkou Reservoir, China. J. Environ. Inf., 25(1), 60-70.

Thompson, L.M., Manen, F.T., Schlarbaum, S.E., DePoy, M., 2006. A spatial modeling approach to identify 
potential butternut restoration sites in Mammoth Cave National Park. Restor. Ecol. 14, 289-296. DOI: 10.1111/j.1526-100X.2006.00131.x.

Urban, D.L., Minor, E.S., Treml, E.A., Schick, R.S., 2009. Graph models of habitat mosaics. Ecol. Lett. 12, 260-273. DOI: 10.1111/j.1461-0248.2008.01271.x.

White, D., Fennessy, S., 2005. Modeling the suitability of wetland restoration potential at the watershed scale. Ecol. Eng. 24, 359-377. DOI: 10.1016/j.ecoleng.2005.01.012.

Wingard, G.L., Lorenz, J.J., 2014. Integrated conceptual ecological model and habitat indices for the southwest Florida coastal wetlands. Ecol.Indic. 44, 92-107. DOI: 10.1016/j.ecolind.2014.01.007.

Xia, X.H., Wu, Q., Mou, X.L., Lai, Y.J., 2015. Potential impacts of climate change on the water quality of different water bodies. J. Environ. Inf., 25(2), 85-98. DOI: 10.3808/jei.201400263.

Xin, X.Y., Huang, G.H., Sun, W., Zhou, Y., Fan, Y.R., 2015. Factorial two-stage irrigation system optimization model. J. Irrig. Drain. Eng., 142, 04015056. DOI: 10.1061/(ASCE)IR.1943-4774.0000951.

Xue, W.W., 2010. Breeding ecology and habitat selection of oriental white store (Ciconia boyciana) in Yellow River Delta. Anhui: Anhui University. (in Chinese)

Zedler, J.B., 2000. Progress in wetland restoration ecology. Trends Ecol. Evol. 15, 402-407. DOI: 10.1016/S0169-5347(00)01959-5.

Zedler. J.B., Kercher. S., 2005. Wetland resources: status, trends, ecosystem services, and restorability. Annu. Rev. Environ. Resour. 30, 39-74. DOI: 10.1146/annurev.energy.30.050504.144248.

Zhao, Q.Q., Bai, J.H., Huang, L.B., Gu, B.H., Lu, Q.Q., Gao, Z.Q., 2016. A review of methodologies and success indicators for coastal wetland restoration. Ecol. Indic. 60, 442-452. DOI: 10.1016/j.ecolind.2015.07.003. 
Previous state

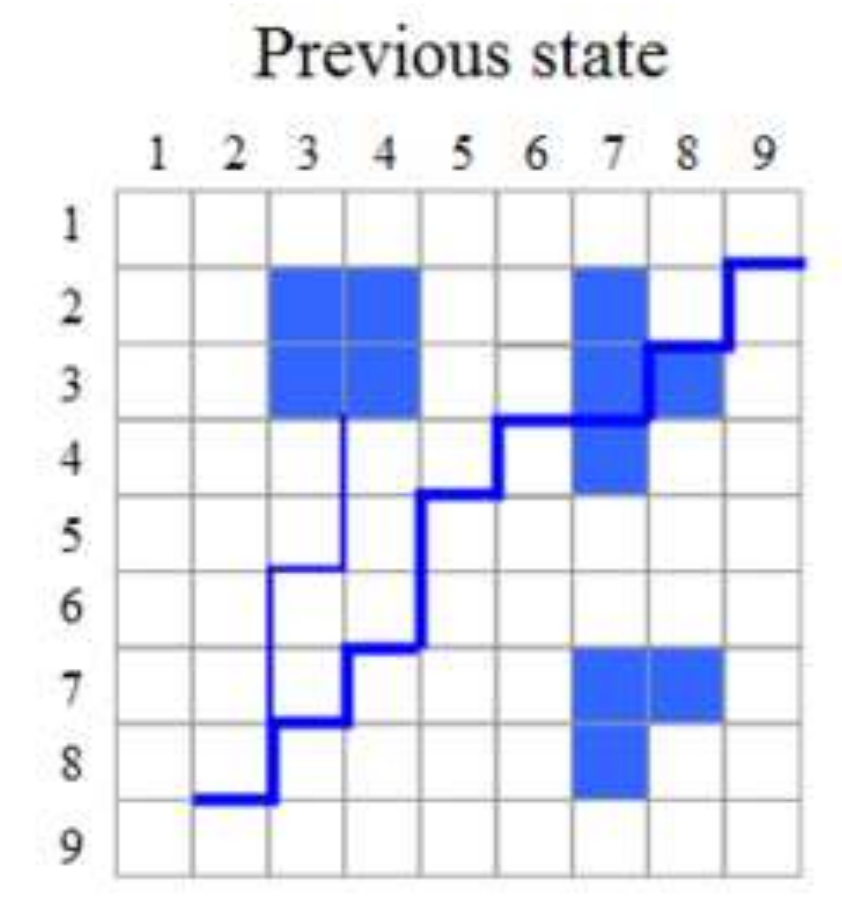

Current state

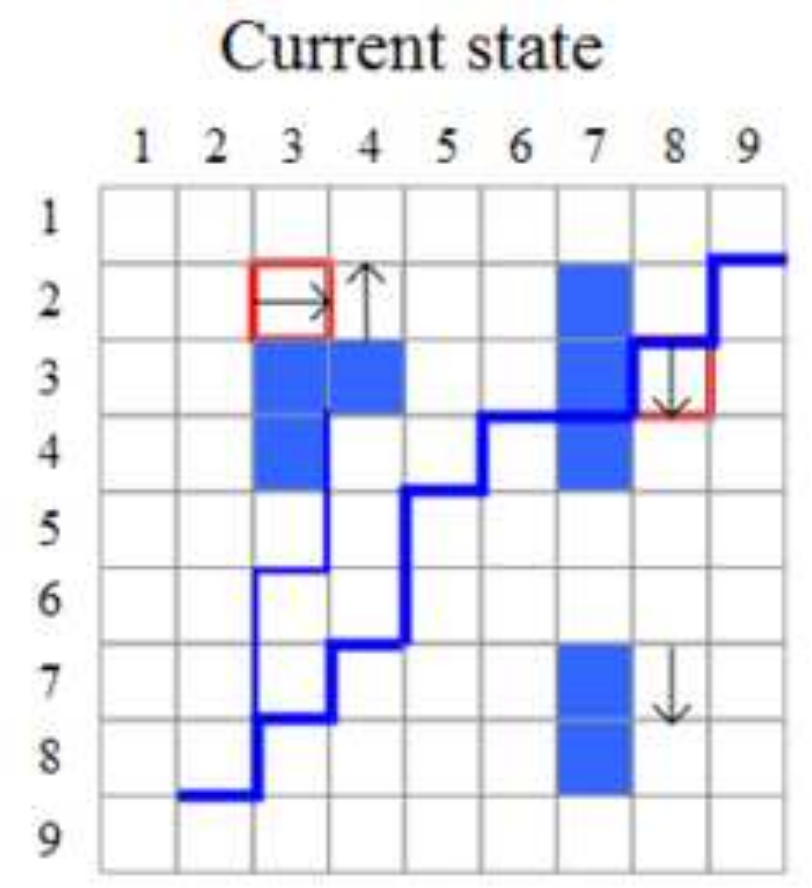
드 River and channel $\square$ Freshwater wetland patch $\square$ Other land cover types
$\uparrow$ Suitable habitat $\quad \rightrightarrows$ Marginally suitable habitat $\downarrow$ Unsuitable habitat $\square$ Potential restoration area




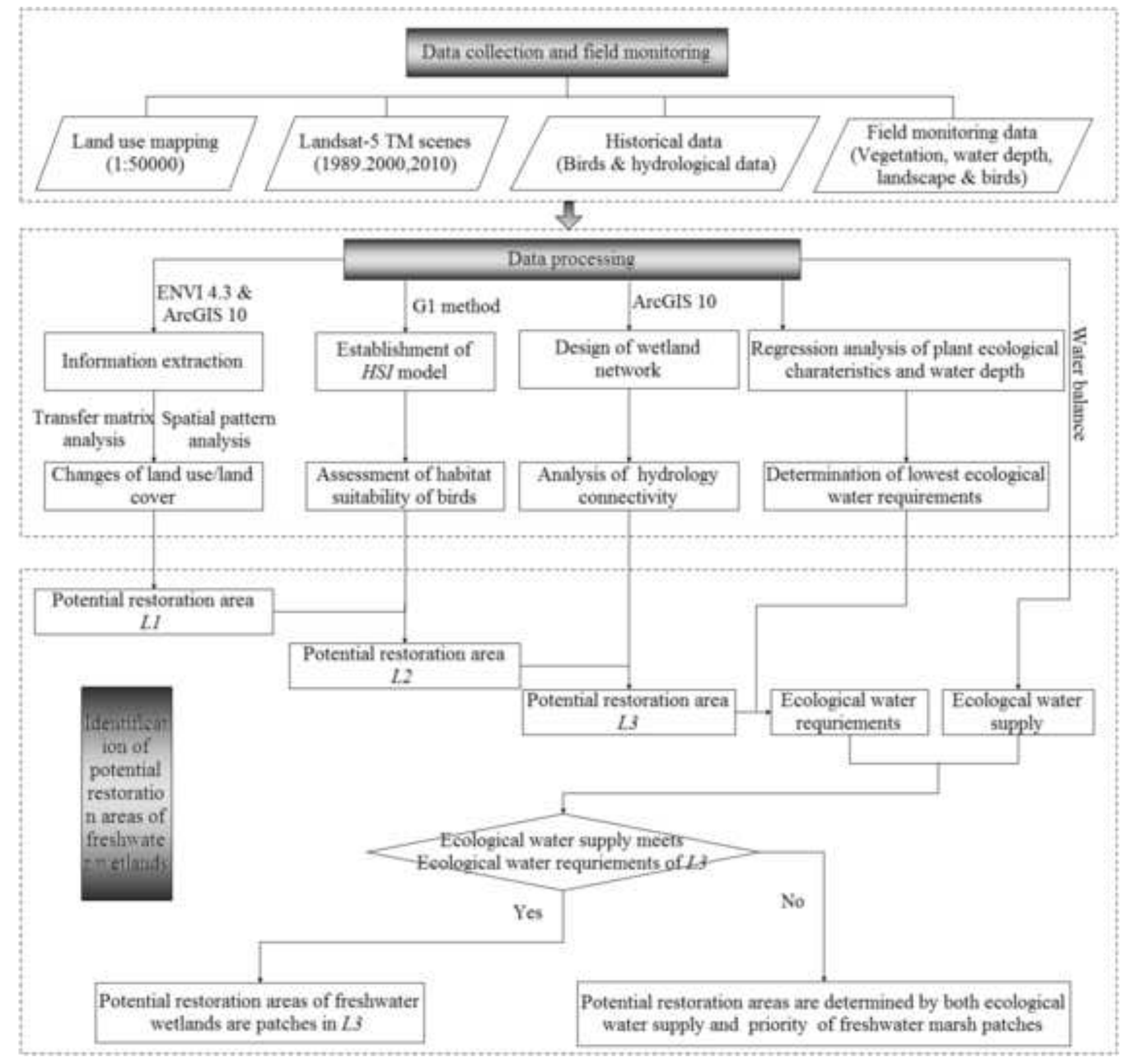



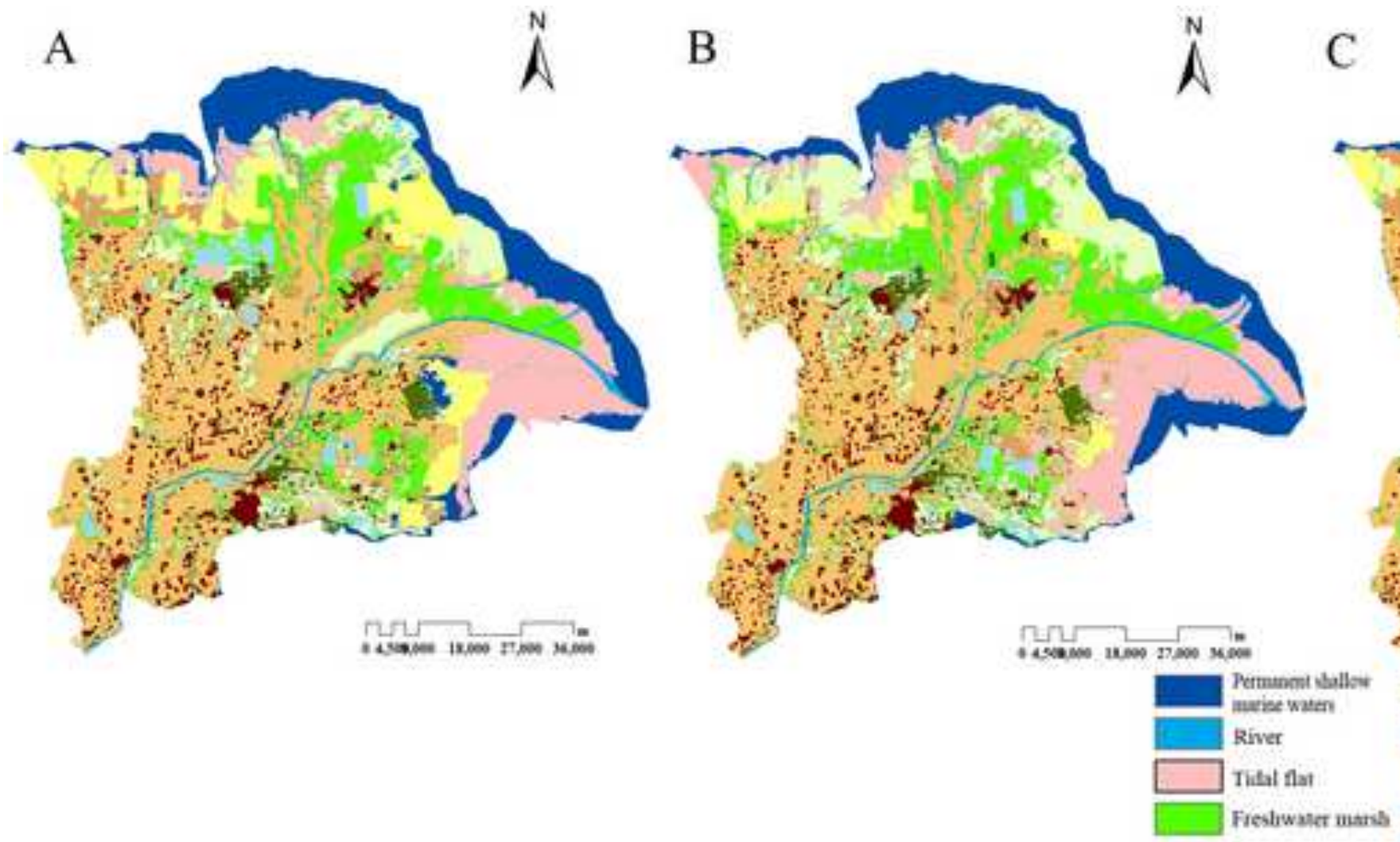

C

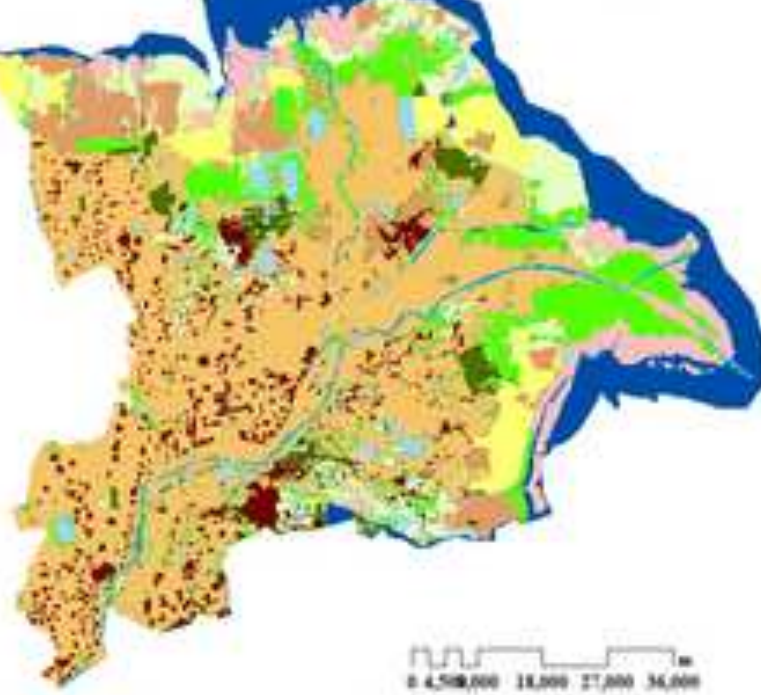

$\square$ Salt marst

Water stocage aes

Aruaculture pond

$\underset{7 \rightarrow m}{3}=$

Ssit poud

Farmland

Coentraction land 


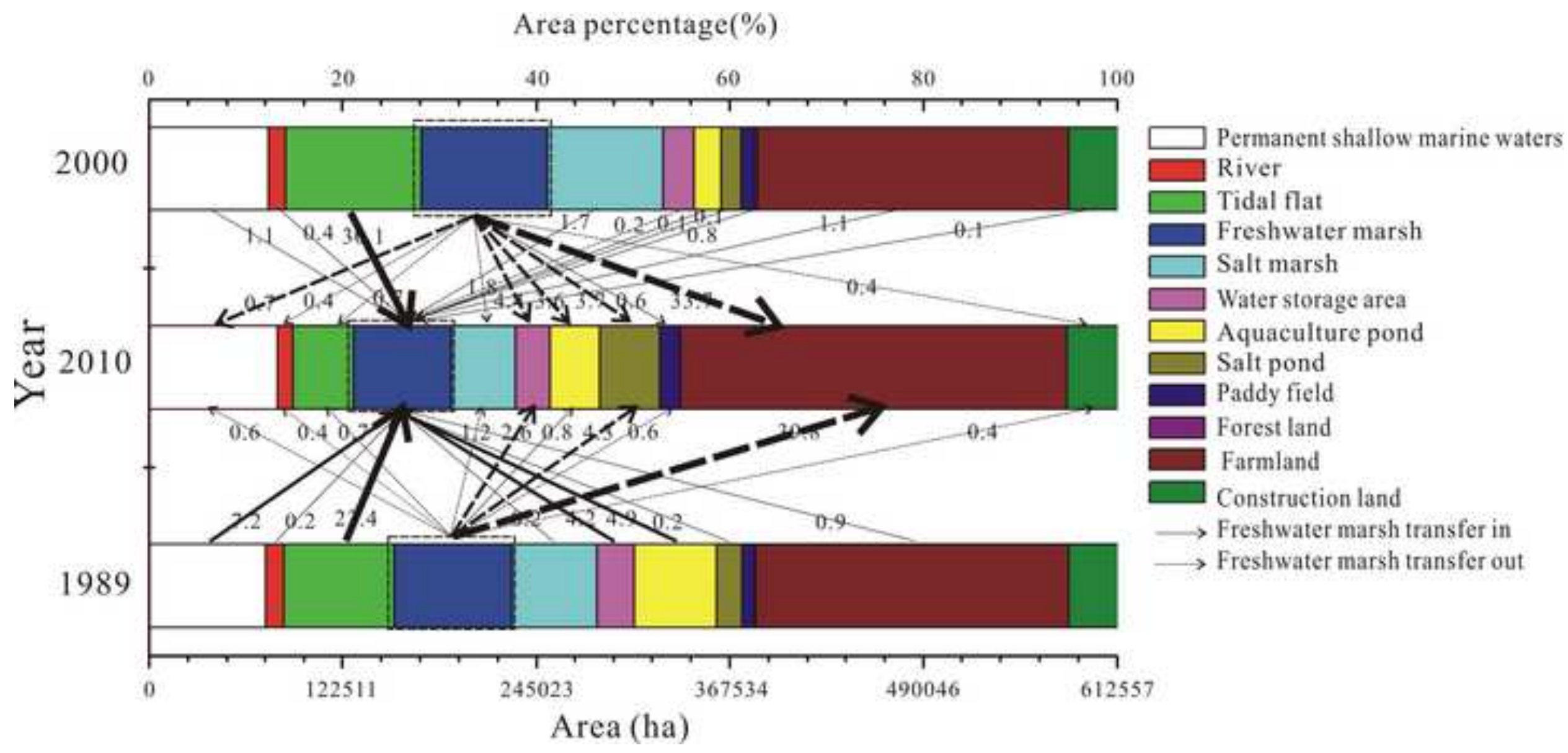




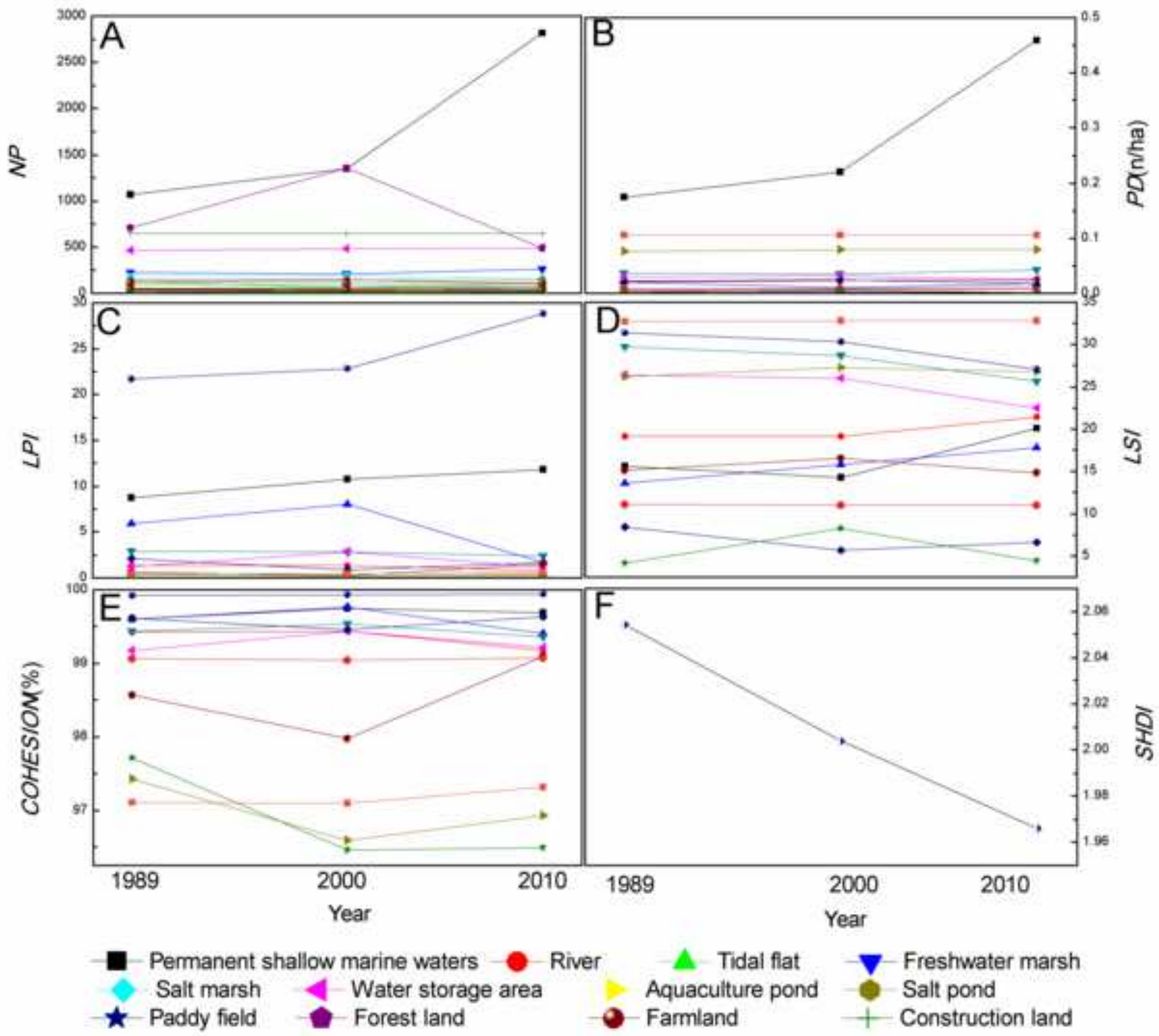



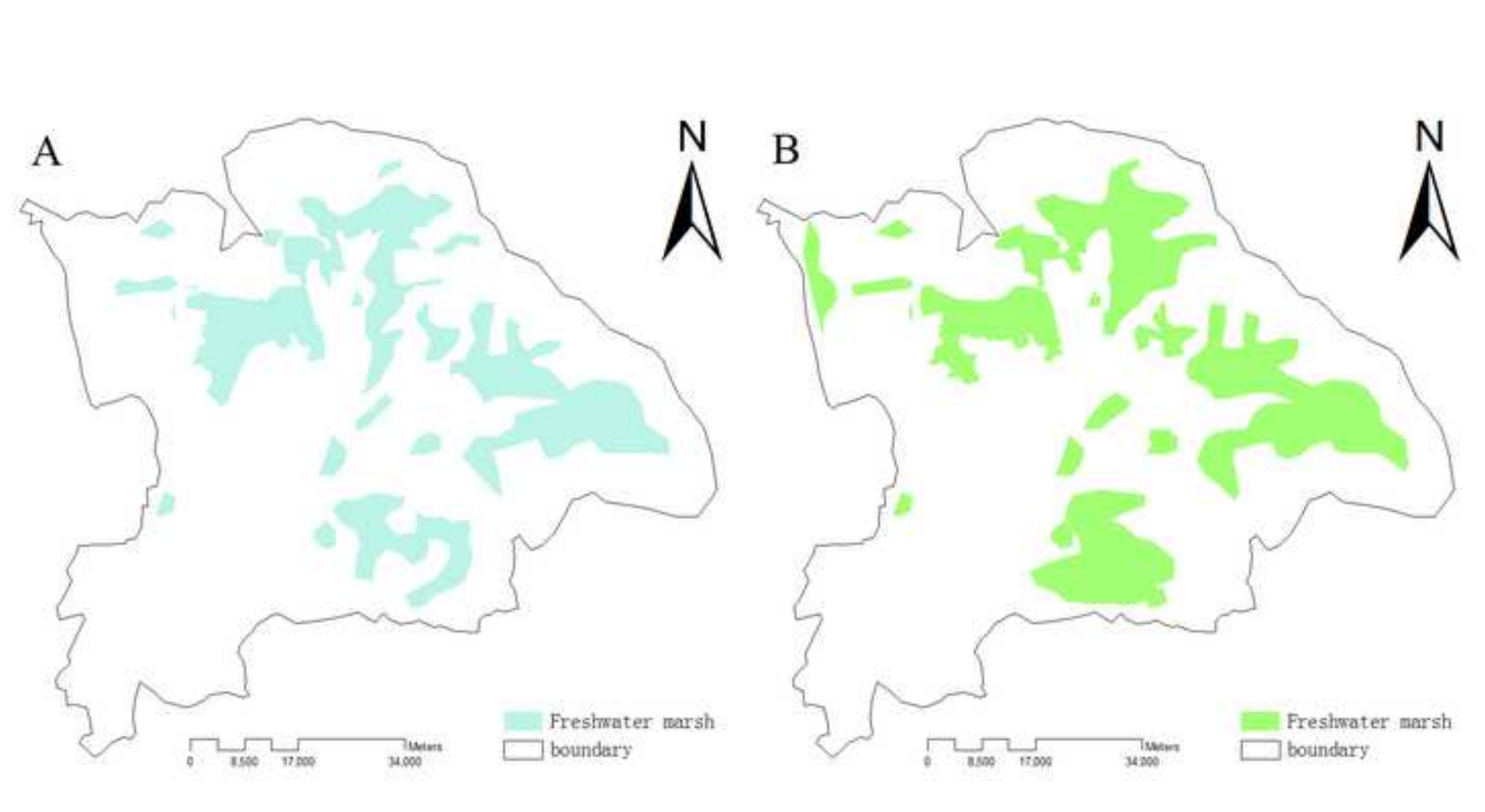

(

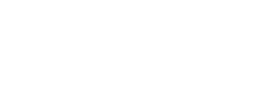




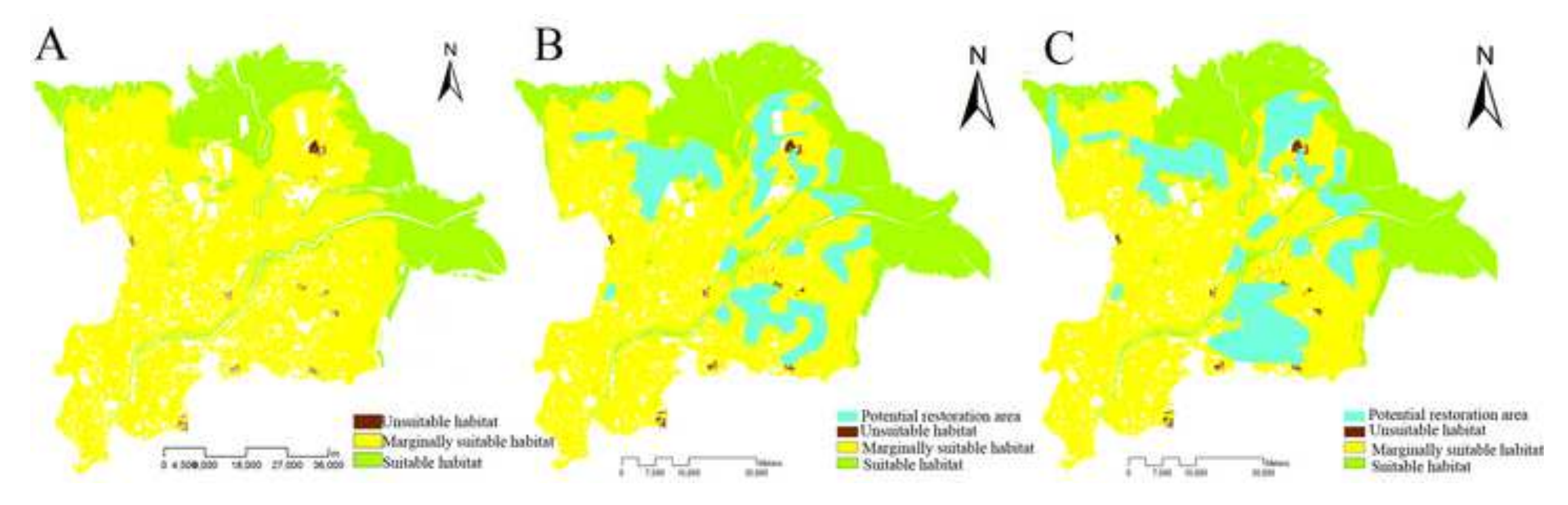

A

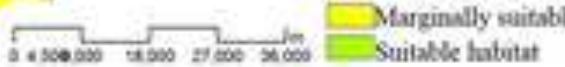

-
Marginally suitable babiat
- Utuatable hasteat

Samitable hahisal

\section{Figure 7}

(n)



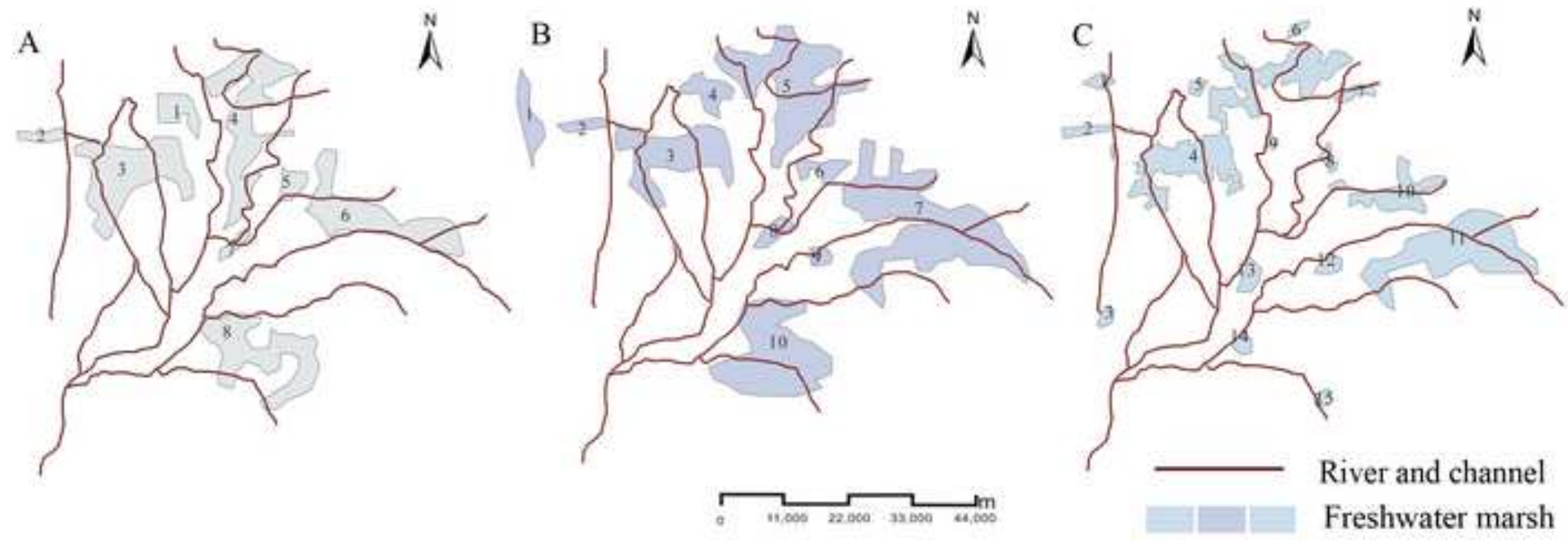
A

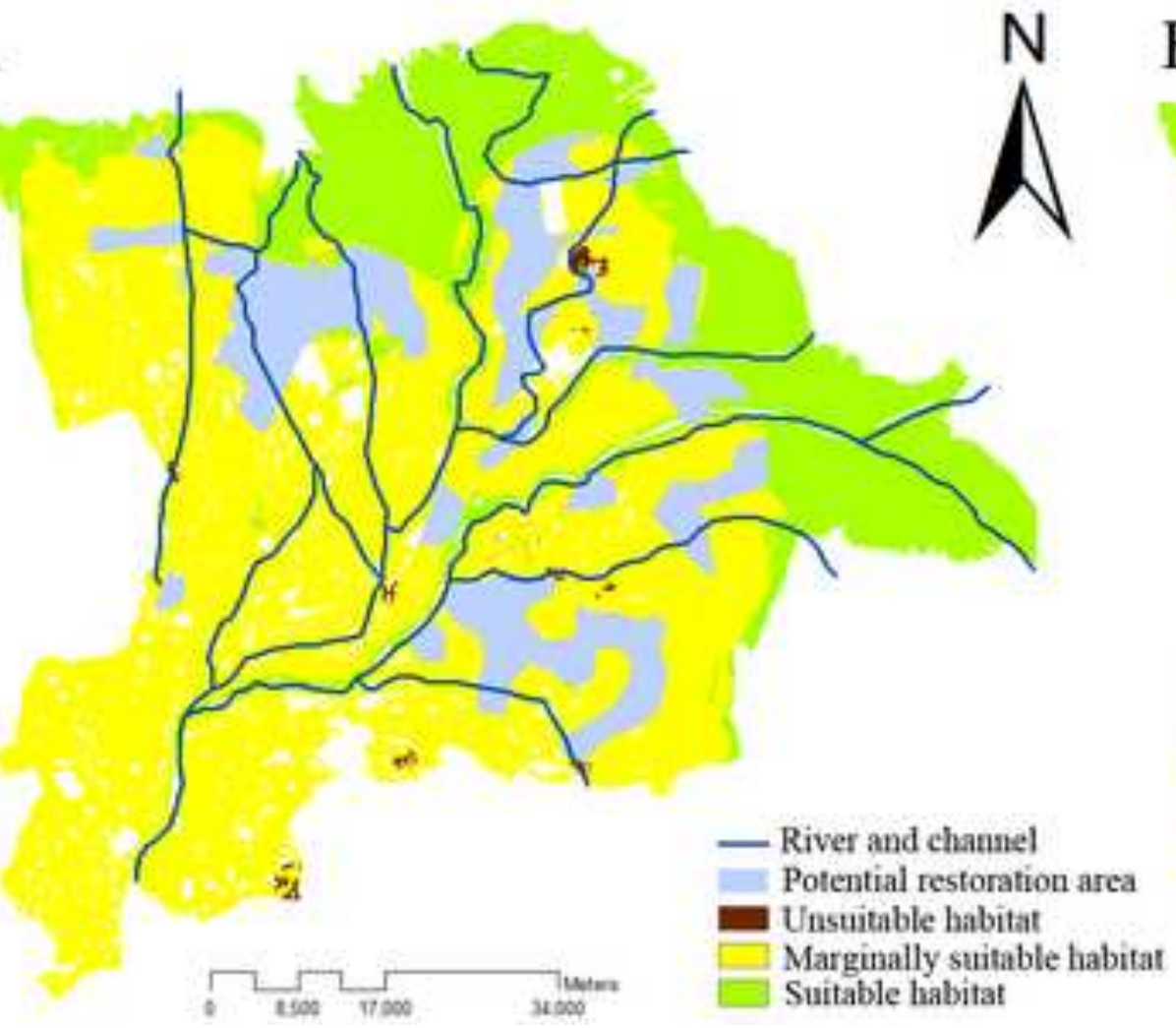

B
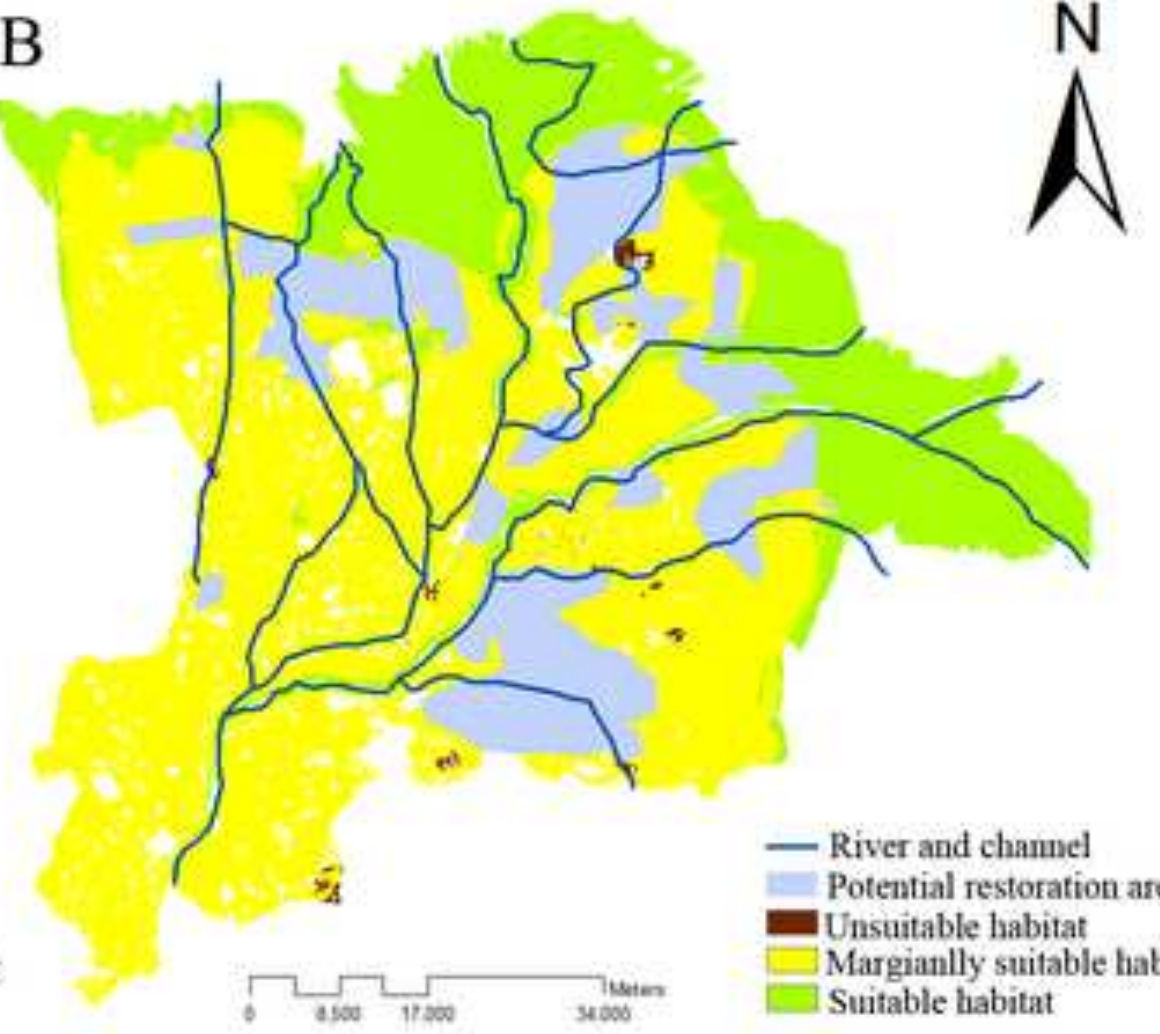

- River and chamel Potential restoration area

Unsuitable habitat

Margianlly suitable habitat

Suitable habitat 

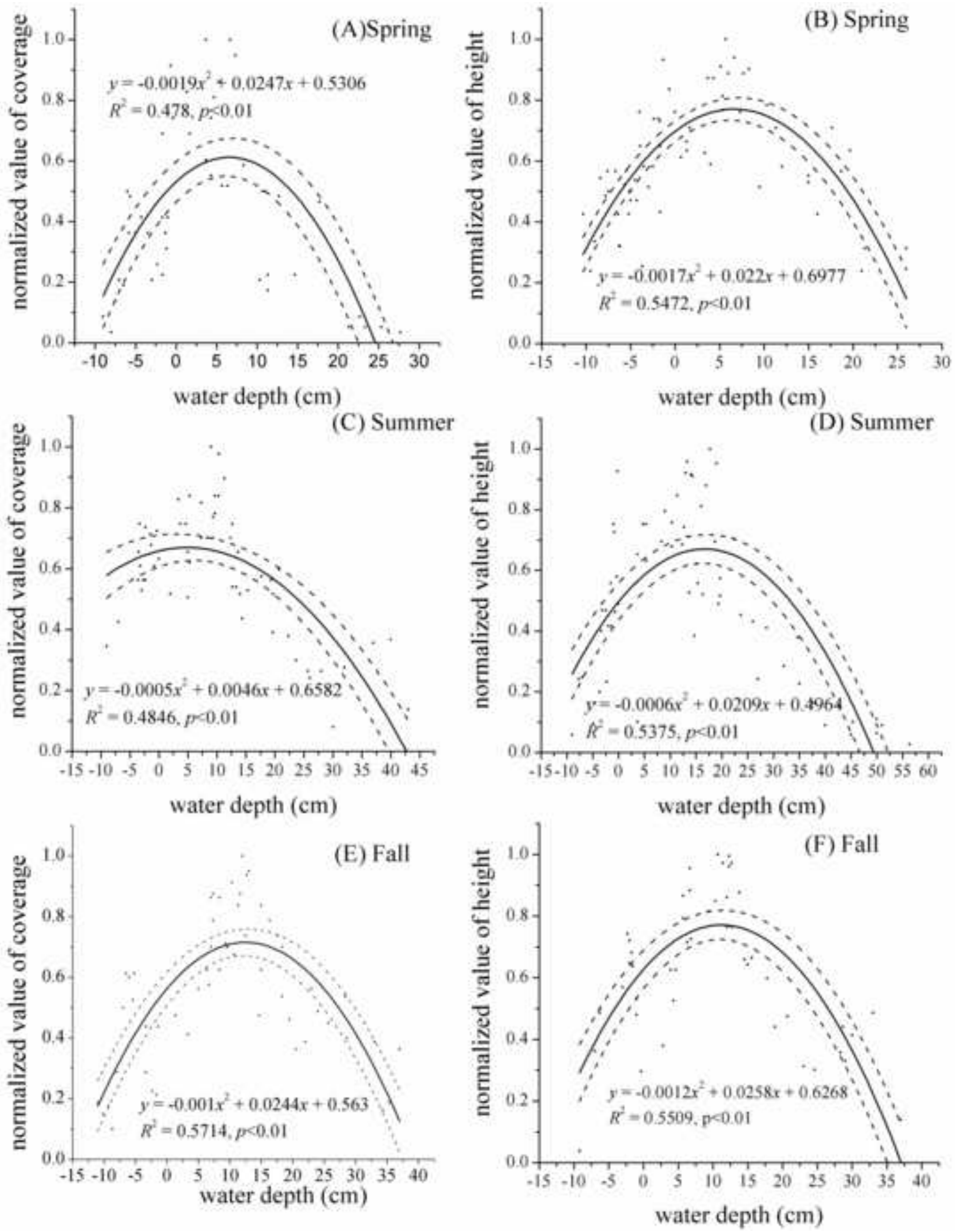